\title{
SEMELHANÇA CLÍNICO-HEMATOLÓGICA INICIAL DA TOXOPLASMOSE ADQUIRIDA, AGUDA, COM FEBRE TIFÓIDE
}

\section{Vicente Amato Neto, Gerson Mazzucato, Mauro Shosuka Asato e João Silva de Mendonça}

\begin{abstract}
Na fase aguda da toxoplasmose adquirida podem ocorrer anormalidades clínicas e hematológicas semelhantes às que, habitualmente, fazem parte da febre tifóide. Com base em casuística composta por 27 pacientes são salientados esses fatos, constituidos sobretudo por febre, hepatesplenomegalia, leucopenia, desvio neutrofilico à esquerda e aneosinofilia, com subseqüente aparecimento de linfocitose, composta inclusive por linfócitos atípicos. Essas verificações merecem divulgação e atenção, em virtude das implicações de ordem assistencial que envolvem.
\end{abstract}

Palavras chaves: Toxoplasmose. Febre tifóide. Aspectos clínico-hematológicos.

A toxoplasmose, após fase na qual alguns pesquisadores, no Brasil e em outros paises, labutaram como fito de esclarecer aspectos básicos a ela ligados e a fixar a real dimensão que tem em termos médicoassistenciais, pode hoje, sem dúvida, ser encarada como afeç̧ão não excepcional e digna de abordagem em trabalhos clínico-profissionais cotidianos.

A infecção humana devida ao Toxoplasma gondii é congênita ou adquirida, pós-natal. Esta modalidade apresenta-se conforme diversos tipos, decorrentes de primordial comprometimento de determinados setores orgânicos. Assim sendo, ençntram-se bem definidas as formas assintomática, oligossintomática, exantemática, miositica, miocárdica, pulmonar, hepática, ocular, meningencefalitica e ganglionar, que corresponde à situação na qual sucede confusão com a mononucleose infecciosa. Quadro reumático é, por alguns, incorporado a essa relação e, presentemente, está também em foco a participação da toxoplasmose no contexto da sindrome de imunodeficiência adquirida, rotulada como AIDS ou SIDA 27 .

No ambiente onde exercemos atividades, a toxoplasmose é doença freqüentemente reconhecida, graças aos ensinamentos e pesquisas de estudiosos que se interessam por ela. Nesse contexto, deparamos com situação que se foi repetindo e tornou conveniente descrevê-la e divulgá-la. Trata-se da verificação de um

Trabalho do Serviço de Doenças Transmissiveis, do Hospital do Servidor Público Estadual "Francisco Morato de Oliveira", São Paulo, SP.

Recebido para publicação em $7 / 12 / 84$ aspecto peculiar, traduzido por início das manifestações de molde a gerar cogitação de febre tifóide, com base nos sintomas, sinais e alterações hematológicas presentes.

\section{CAUSUÍSTICA E MÉTODOS}

Compõem nossa causuística 27 pacientes, assistidos no periodo que decorreu de março de 1970 a outubro de 1983. As observações se sucederam em atividades rotineiras, sem planejamento prospectivo, no Serviço de Doenças Transmissiveis, do Hospital do Servidor Público Estadual "Francisco Morato de Oliveira", de São Paulo.

Quanto ao sexo, 15 enfermos eram do masculino e 12 do feminino. No que tange à idade, em anos, especificamos adiante a distribuição numérica conveniente: até cinco-1; de seis a dez-2; de 11 a 20-7; de 21 a $30-4$; de 31 a $40-7$; de 41 a $50-5$; superior a $50-1$.

No decurso da fase de internação, ao lado da essencial observação clínica e do necessário registro de dados relativos à evolução, providenciamos a execução de hemogramas e de hemoculturas, havendo também solicitação de outros comuns exames subsidiários, sempre que apropriado.

A documentação etiológica atinente à toxoplasmose sempre decorreu da positividade de provas sorológias (imunofluorescência indireta para anticorpos IgG e IgM antitoxoplasma, fixação do complemento, hemaglutinação passiva) e a confirmação decorreu sistematicamente da presença de anticorpos $\operatorname{IgM}^{134}$. 
Amato Neto V, Mazzucato G, Asato MS, Mendonça JS. Semelhança clínico-hematológica inicial da toxoplasmose adquirida, aguda, com febre tifóide. Revista da Sociedade Brasileira de Medicina Tropical 18: 161-163, Jul-Set, 1985
DIAS DE EVOLUCÁ̃O
35
II
13
18

ENFARTAMENTO DE LINFONODOS

HEMOGRAMA

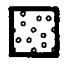

3 悬

PROVAS SOROLÓGICAS PARA TOXOPLASMOSE

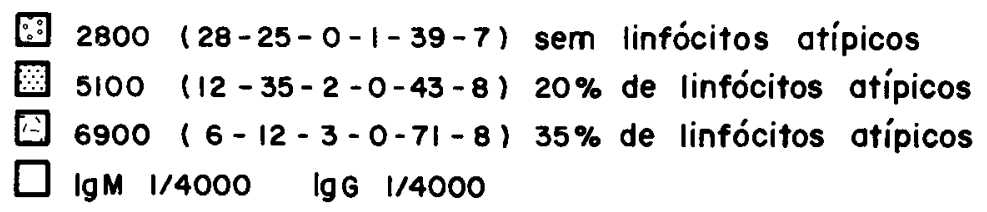

Figura I-Ilustração de um dos casos, para exemplificar eventos configurados no presente relato.

Para tratamento especifico recorremos a medicamentos diversos, tais como sulfadiazina ou sulfadoxina associadas à pirimetamina, sulfametoxazol e espiramicina, prescritos conforme esquemas tracionalmente usados 2 .

Os 27 doentes constituintes do grupo analisado representaram a quinta parte dos com toxoplasmose aguda atendidos na etapa mencionada.

\section{RESULTADOS}

Levando em conta as manifestações mais proeminentes, estipulamos as percentagens que se encontram a seguir indicadas: febre $(93 \%$; média da fase de persistência: 21 dias); hepatomegalia: $78 \%$; esplenomegalia: $63 \%$; enfartamento de linfonodos superficiais e, sobretudo, de cervicais: $33 \%$; astenia: $85 \%$; mialgia: $52 \%$; cefaléia: $41 \%$.

O hemograma inicialmente revelou leucopenia, acentuado desvio à esquerda referente aos neutrófilos e aneosinofilia (52\%), estando ausente linfocitose. Após etapa com duração média de 6,8 dias, esse exame passou a mostrar número total de leucócitos normal ou pouco aumentado, além de volta à habitual da cifra relativa aos eosinófilos; ainda mais, começou a evidenciar, por vezes, pequena ou moderada eosinofilia, surgindo porém, costumeiramente, linfocitose $(39 \%$ a $67 \%)$, composta inclusive por linfócitos atípicos, vistos segundo valores diversos e, na maioria das situações, variáveis de $10 \%$ a $50 \%$.

As hemoculturas nunca demostraram microrganismos, os demais testes laboratoriais não documentaram anormalidades dignas de menção e as evoluções foram satisfatórias, tendo havido instituição de tratamentos apropriados para a toxoplasmose. Processou-se sempre arrefecimento do quadro agudo, sem acontecimentos indicativos de gravidade, seqüelas ou óbitos.

Obtivemos resultados de dez reações de Widal, relativas a igual número de pacientes. Como constatações dignas de citação, ao lado de negatividades e de aglutinações em teores baixos, inferiores a $1 / 200$, apuramos três cifras significativas (antígeno tífico $0-1 / 200$ e 1/320; Salmonella paratiphy A: 1/800) sem que febres tifóide ou paratifóide tivessem ocorrido.

Através da Fig. 1 ilustramos um dos casos, para exemplificar eventos configurados neste relato.

\section{DISCUSSÃO}

A particularidade clínico-laboratorial que no momento relatamos é inédita, se considerada a inexistência prévia de registro idêntico na literatura médico-científica, ressalvadas duas comunicações em congressos que tiveram lugar no Brasil ${ }^{5} 6$. A despeito disso, em São Paulo ela é conhecida por diversos 
Amato Neto V, Mazzucato G, Asato MS, Mendonça JS. Semelhança clinico-hematológica inicial da toxoplasmose adquirida, aguda, com febre tifóide. Revista da Sociedade Brasileira de Medicina Tropical 18: 161-163, Jul-Set, 1985

profissinais, que já vêm usando-a em tarefas de natureza diagnóstico-terapêutica cotidianas. Em face dessas circunstâncias, decidimos conceder a ela conotação oficial e efetiva, consumando esta publicação.

A semelhança, no inicio do processo, com febre tifóide, é o fulcro desta nossa informação. Ela teve nexo com elementos de ordem clínica, tais como febre e hepatesplenomegalia, mas essencialmente com o resultado do hemograma, evidenciador de leucopenia, desvio neutrofilico à esquerda e an.eosinofilia. Mudanças subseqüentes, consubstanciadas mormente por linfocitose e participação de linfócitos atípicos, com presença, por vezes, de outras alterações complementares, entre as quais convém especificamente destacar a linfadenopatia, criaram panorama vinculado à sindrome da mononucleose e conseqüente comprovação de toxoplasmose.

Vários doentes chegaram a receber cloranfenicol, em virtude da confusão com febre tifóide, e esse comportamento atesta realisticamente conduta adotada por experientes clínicos, familiarizados com processos infecciosos.

Cifras não normais advindas da reação de Widal suscitam especulações, no âmbito de respostas cruzadas, antigenicidade comum e fenômenos congêneres. Não obstante, é melhor, agora, só registrar o que se passou, estimulando estudos inerentes a essa questão.

Almejamos que a circunstância clínico-hematológica presentemente descrita sirva para orientar atendimentos, na linha de frente de trabalhos médicoprofissionais relativos a duas enfermidades não excepcionais no Brasil.

\section{SUMMARY}

Clinical and hematological disturbances, similar to those usually described in typhoid fever, may be found in acute acquired toxoplasmosis. Based on the analysis of 27 patients these aspects are emphasised, considering fever, hepatosplenomegaly, leukopenia, neutrophil left shuft and the absence of eosinophils, subsequently followed by lymphocytosis, with atypical lymphocytes. Due to their clinical implications in patient care, these aspects deserve attention.

Key words: Toxoplasmosis. Typhoid fever. Clinical and hematologic features.

\section{REFERÊNCIAS BIBLIOGRÁFICAS}

1. Amato Neto V, Camargo ME, Mendonça JS, Levi GC, Oselka GW. Observações sobre a pesquisa de anticorpos IgM antitoxoplasma, por imunofluorescência, no soro de pacientes com toxoplasmose adquirida, forma linfoglandular. Revista do Instituto de Medicina Tropical de São Paulo 14: 264-272, 1972.

2. Amato Neto V, Campos R, Baruzzi RG, Duarte MIS. Toxoplasmose. Sarvier, Sào Paulo, 1982.

3. Camargo ME, Leser PG. Diagnostic information from serological tests in human toxoplasmosis. II - Evolutive study of antibodies and serological patterns in acquired toxoplasmosis, as detected by hemagglutination, complement fixation, IgC - and IgM - immunofluorescence tests. Revista do Instituto de Medicina Tropical de São Paulo 18: 227-238, 1976.

4. Camargo ME, Leser PG, Leser WSP. Diagnostic information from serological tests in human toxoplasmosis. I - A comparative study of hemagglutination, complement fixation, IgG - and IgM - immunofluorescence tests in 3,752 serum samples. Revista do Instituto de Medicina Tropical de São Paulo 18: 215-226, 1976.

5. Mazzucato G, Asato MS, Mendonça JS, Amato Neto V. Toxoplasmose aguda: semelhança clínico-hematológica inicial com febre tifóide; relato de 27 casos. In: Resumos do XX Congresso da Sociedade Brasileira de Medicina Tropical e I Congresso da Sociedade Latino-Americana de Medicina Tropical, Salvador, p. 136, 1984.

6. Mendonça JS, Amato Neto V, Rodrigues EAC, Andrade JG, Sado K, Zanini LA. Semelhança clinico-hematológica da toxoplasmose aguda com a febre tifóide. In: Resumos do XI Congresso da Sociedade Brasileira de Medicina Tropical, Rio de Janeiro p. 213, 1975.

7. Scott RJ. Toxoplasmosis. Tropical Diseases Bulletin 75: 809-827, 1978. 